\title{
How many Medical specialists do Ministry of Health- Sri Lanka need by 2025: Use of system dynamics modelling for policy decisions
} MDK De Silva

\begin{abstract}
Introduction The Ministry of Health is the largest health care provider in Sri Lanka in terms of funding, coverage and human resources. Long duration and high training cost of a medical specialist highlights the importance of health human resource planning. Ministry of Health, Sri Lanka has no scientific cadre planning for medical specialists.

Methods System dynamics, an analytical modelling approach and a methodology for studying complex feedback systems was used. Two sub models of "need" and "supply" were developed and simulated over a period of 10 years from 2016 to 2025 .
\end{abstract}

Results By December 2015 there were 1860 clinician medical specialists with an average age of 46.8 years, in the government hospitals in Sri Lanka. In the surgical group of specialties the Proposed Training Rate is more than Current Training Rate while in Medical and Paediatric groups and in Radiology, Anaesthesiology, Psychiatry, Dermatology and Hematology Proposed Training Rate is less than the Current Training Rate.

Conclusion In Surgical specilities the number of trainees enrolled in the Pre-MD programme should be increased from 55 to 71 and while in Medical specilaities the number of trainees enrolled in PreMD programmes should be reduced from 107 to 68 and in the Paediatric specialities from 47 to 39 . During the 2016-2025 period, 765 specialists will be lost to the Ministry of Health costing nearly Rs 7.6 billion and there will be 4050 consultants by 2025 , which is a $120 \%$ increase.

Ceylon Medical Journal 2017; 62:141-148

DOI: http://doi.org/10.4038/cmj.v62i3.8517

\section{Introduction}

The Ministry of Health, is the largest health care provider in Sri Lanka in terms of funding, coverage and human resources. As per latest available national health accounts Sri Lanka spent Rs. 260 billion as current health expenditure and 21 billion as capital expenditure for health care in 2013 [1]. Government of Sri Lanka, through the Ministry of Health, has catered for 53.8 million out-patients and 5.9 million in-patients in 2013, spending Rs. 165 billion, which was around $1.92 \%$ of the total GDP [1].

The Government of Sri Lanka is the main financier for health care delivery in Sri Lanka accounting for $55 \%$ of the total health care expenditure [1]. Sri Lanka's current GDP per capita of USD 3,600 falls in the lower-middle-income category, and has grown at a compound annual growth rate of $13 \%$ in the last 10 years. Personal care and health expenses have also increased from $4.3 \%$ of total household expenditure in 2006 to $5.3 \%$ in 2013 as people become more health-conscious as income levels rise. Should Sri Lanka continue its current GDP growth trajectory of $6 \%-7 \%$ per annum, it should reach the level of upper-middleincome economies in the next two-three years [2].

However, Sri Lanka's total healthcare expenditure as a percentage of total GDP is one of the lowest in the world at around 3.5\%. Yet healthcare per capita in Sri Lanka is significantly higher than in most other Asian and middle-income countries [2]. This is reflected for example in high hospital bed penetration of 4.0 beds per 1,000 population.

Ministry of Health Sri Lanka.

Correspondence: MDKDeS, E-mail: <dileepdenta@yahoo.com>. Received 5 April 2017 and revised version

accepted 24 July 2017. 
Sri Lanka is one of the few countries in the world which provides free medical education at undergraduate and post graduate levels. The Government of Sri Lanka spends nearly Rs. 10 million for post graduate training at the tax payers' expense, to produce a medical specialist [3]. Furthermore, due to the very long duration of training, decisions taken with regard to training will take a long time to materialize, highlighting the importance of optimizing the health human resource utilization in general and that of medical specialists in particular.

\section{Health human resource perspective}

The provision of human resources in the health field is a logistical task of great complexity. There is a need for national level long-term planning in the context of uncertainty in training numbers, cadre vacancies, availability of equipped hospitals, and global demand. [4]. The labour market for health professionals must be extremely adaptable in order to absorb swiftly, the changes required by new technologies, scientific advances, societal demands, and new models of organization.

A shortage of health professionals, especially medical specialists, whether because of poor planning or barriers to entry in the profession, appears to be a problem in many developed countries. Planning for health human resources has become a high priority for Organization for Economic Cooperation and Development (OECD) countries. It was the focus of the World Health Organization (WHO) annual World Health Report for 2006, and at present, it is high on the international agenda [5].

There is no perfect method for planning for specialist medical doctors. None of the methods have been applied in a pure form, although Australia, Canada, Germany, Netherlands and the United Kingdom have a long history and experience with 'need-based' planning.

The United States of America is a good example of medical assignment based on demand and the market. However, in practice, this approach is mixed with what is known as the 'professional' model, by which the medical fraternity has some control on the entry into the profession [6].

In Sri Lanka too, medical professional associations have a say in decisions about the number of specialists to be trained, sharing the United States aspects of the 'professional' model. Moreover, the organisation of health care in Sri Lanka is based on the lines of the National Health
Service of the UK, which is fully funded by taxes and provides universal coverage. However, the Ministry of Health in Sri Lanka lacks scientific cadre planning for medical specialists. This study was carried out to fill that void.

\section{Methods}

\section{System Dynamics}

System dynamics is an analytical modelling approach and a methodology for studying complex feedback systems. Essentially, it is an aid to understanding the behaviour of complex systems over time. System dynamics describes how the behaviour and relationships of separate components of a system contribute to the behaviour of the system as a whole [7]. System dynamics has two aspects, qualitative and quantitative. The quantitative aspect involves the development of stock-flow models (as done in this study), which are essentially compartmental differential equation models, solved numerically by discretization [8].

Specialized computer software (Stella Version 9) was used for this purpose and the calculations were based on mathematical equations using Euler algorithm [9]. Two sub models of "need" and "supply" described below; were developed and connected to one and other and simulated over a period of 10 years from 2016 to 2025 .

\section{The sub-model of supply}

The sub-model of supply shows the worklife cycle of medical specialists from training until retirement or death. The cycle begins with admission to the Post Graduate Institute of Medicine, University of Colombo as a Post Graduate trainee. Enrolment is very competitive and limited.

Training rates of nearly 50 specialties was a key parameter in the model. Here the author considered the Current Training Rate (CTR) as the average number of trainees enrolled per year between 2010-2015 and the Proposed Training Rate (PTR) as the average number of trainees that need to be recruited per year from 2017-2015. Retirement age was considered as 60 years.

\section{The sub-model of need}

The need sub-model was based on normative standards of need for each specialty or group of specialties in the baseline year 2015 and over successive years. The need for specialists in Sri Lanka, in the baseline year was estimated from the information on deficit (the positions unfilled in the 
established hospital hierarchy). Starting with this baseline year, the evolution of estimated future needs was based on population characteristics, health care system goals (future health care levels to guarantee the population health), future health care delivery settings and facility staffing norms.

Following input variables were considered in order to project the number of clinician specialists by specialty that the Ministry of Health needs by 2025. Age structure of the current specialists and retirement rate; attrition rate (loss to local university, defence and private sector and global market) per year based on past trend analysis; training rate (number trained per year by the PGIM) considered as Current Training Rate and Proposed Training Rate; training duration; training capacity; in-situ number of specialists; economic growth of the country; health sector growth in the country [10]; growth of health insurance coverage; demographic changes [11]; need for health services (Health Service System Goals) [12]; facility staffing norms and Brexit factor [13].

The model simulates the evolution of supply and demand of medical specialists in a predictive timeline from 2016 to 2025 . As the key output parameters, system dynamics model generates the number needed to be trained per each year (Proposed Training Rate) and the number of specialists that would be available each year up to 2025. Schematic view of the model is shown in the supplementary figure.

\section{Model Validation}

For model validation two basic methods were used, namely structure and behavior based validation. In structure based validation, author was concerned about model formulation and ensured that the model is suitable for its purpose and is consistent with the real-world system. Behaviour based validation involved conducting model simulations to probe the validity of the model construction. Once the simulation runs were performed the output parameters were judged to be realistic and convincing by those with day to day experience of the real system under consideration. Model validity was further enhanced by extreme condition testing and looking for surprise behavior by simulation with extreme values [14].

\section{Results}

Model results are presented for the period 2016-2025. By December 2015 there were 1860 clinician medical specialists, working in the Line Ministry and Provincial Hospitals in Sri Lanka. They belonged to nearly 50 specialties/sub specialties with an average age of 46.8 years.
These numbers included around 150 acting clinician consultants and excluded Consultant Community Physicians (around 65), Consultant Medical Administrators (around 20) and approximately 25 consultants belonging to numerically insignificant specialties. This gives a country ratio of 1 medical specialist to 11,183 population with severe maldistribution between districts.

Tables 1-5 illustrate, by specialty, the attrition and retirement during 2016-2025, Current Training Rate (CTR), Proposed Training Rate (PTR), number available as at end of 2015 and the predicted number by 2025 . Considering the broader groups of specialties; in the Surgical Group of specialties, in all 12 specialties considered therewithin, Proposed Training Rate is either more or equal to the Current Training Rate (Table 1).

Within the Medical Group of specialties, in General Medicine the Proposed Training Rate is much less than the Current Training Rate (Table 2). However, in most of the sub-specialties within this group, the Proposed Training Rate does not differ much from Current Training Rate.

In the category of "Other group of specialties" (Table 3) in most specialties the Proposed Training Rate does not differ much from the Current Training Rate. However, Proposed Training Rate in Radiology, Anesthesiology, Psychiatry, Dermatology and Hematology is less than the Current Training Rate. In Histopathology, the Proposed Training Rate is higher than the Current Training Rate.

In the Paediatric group of specialties (Table 4), the Proposed Training Rate for general paediatrics is very much less than the Current Training Rate. However all the sub-specialties within this group have a higher Proposed Training Rate training rate than its Current Training Rate.

In the group of dental specialties (table 5), all three specialties showed a lower Proposed Training Rate than Current Training Rate. However, the difference between the Current Training Rate and Proposed Training Rate is small.

\section{Discussion}

Current cohort of medical specialists will remain in the system for around 13 years before they retire from Government service. In surgical specialties the number of trainees enrolled in the Pre-MD programme should be increased from current rate of 55 to 71 per year. However it should be done while ensuring that the correct number is selected for different surgical speciliaties (as shown in table 1) on completetion of MD Surgery 
Examination. If the Proposed Training Rates are implemented there will be 660 specialists in the Ministry of Health by 2025 , in this category, which will be a $92 \%$ increase from the current number of 343. This increase will be after accounting for retirement $(n=131)$ and attrition $(n=143)$.

Special attention of the Postgraduate Institute of Medicine and Ministry of Health is needed in the specialties of Neurosurgery and Cardiothoracic Surgery. Intake to these two specialties must increase substantially with immediate effect (table 1). Conducting separate MD (Surgery) Selection Examinations and provision of a special allowance for these specialists should be considered.

In medical specilaities the number of trainees enrolled in the Pre-MD programme should be reduced from the current rate of 107 to 68 per year. Moreover it should be ensured that the correct number (as illustrated in table 2) is selected for different medical sub speciliaties on completetion of the MD Medicine Examination. If the Proposed Training Rates are implemented there will be 1021 in this category, which will be a $131 \%$ increase during the period 2016 to 2025, of the current number of 436 . This will be after accounting 125 retiring from the Ministry of Health and attrition of 150 by 2025 .

Specilaities identified under the "Other Group of specialities" should either increase or decrease the intake as shown in the table 3 . If the Proposed Training Rates are implemented there will be 1811 in this category, which will be a $121 \%$ increase during the period 2016 to 2025 , from the current number of 819 . This increase will be after considering the loss due to reirement $(n=294)$ and due to attrition $(n=364)$.

In Paediatric specilaities the number of trainees enrolled in the Pre-MD programme should be reduced from 47 to 39 per year, while ensuring that the correct number is selected for different subspeciliaties (as shown in table 4) on completetion of MD Examination. If the Proposed Training Rates are implemented there will be 434 in this category, which will be a $112 \%$ increase during the period 2016 to 2025 from the current number of 205 . This is after accounting for retirement $(n=80)$ and attrition $(\mathrm{n}=91)$.

The intake for dental specialities should be reduced as shown in table 5. If the Proposed Training Rates are implemented there will be 124 in this category, which will be a $118 \%$ increase during the period 2016 to 2025 from the current number of 57. This is after considering the loss due to retirement $(n=26)$ and attrition $(n=17)$.
Considering all specialties together, during 2016-2015 period a total of 765 specialists will be lost to the Ministry of Health due to them joining local universities, defence establishment, private sector or the global market. However, specialists who join the University system, defence forces and private sector will remain in Sri Lanka and will be of service to the Sri Lankan population. Further 656 will retire from government service, at the age of 60 years, but most of them will continue the serve the country in the private sector. Hence when deriving a ratio of a specilaist to population, above facts have to considered.

If the training cost of a medical specialist is taken as Rs. 10 million (rough estimate, considering recurrent expenditure of wages and allowance paid during foreign training) this would amount to a Rs. 7.6 billion loss to Ministry of Health due to attrition during the period under consideration.

System Dynamic Model simulation analysis shows that the Ministry of Health will have 4050 consultants (excluding consultants in Community Medicine and Administration) by 2025 giving a country ratio of 1 medical specialist to 5,309 population with a much improved distribution compared to 2015. Therefore, between 2016-2025 the number of consultants in the Ministry of Health will increase by nearly $120 \%$.

This study analysed the training requirement for the entire country, both public and private. Therefore, the Proposed Training Rates are for both public and private sectors. In general, the model considered the development of sub-specialties and super-specialties and the complexities and overlapping that may occur, when deriving the Proposed Training Rates.

In order to get broader acceptance, the model results were presented and discussed at the following forums [15]; Health Development Council meeting, chaired by the Director General of Health, Sri Lanka Medical Association -Management SubCommittee, Meeting of the Heads of Institutes of the Ministry of Health, chaired by the Minister and relevant Colleges and Associations. Therefore, it should be stated that the final results presented in this article, were prepared with the input and concurrence of the above stake holders. Moreover, cadre requirements proposed here are based on an array of interrelated and intertwined factors mentioned elsewhere. The Ministry of Health has already requested the Postgraduate Institute of Medicine, University of Colombo to consider the above proposals.

The author proposes a study to assess the initial financial requirements, in-order to gainfully employ the new consultants by providing adequate 
infrastructure, equipment and instruments, thereby helping provision of allocations in the health budget. Furthermore, a comprehensive cadre planning must be done for support categories, to complement the proposed specialists' cadre.

\section{Acknowledgements}

Information Technology Unit, Postgraduate Institute of Medicine, Colombo and all professional Colleges and Associations.

\section{Conflicts of Interest}

There are no conflicts of interest.

\section{References}

1. National Health Accounts 2013. Ministry of Health of Indigenous Medicine. Colombo, Sri Lanka 2016.

2. Sri Lanka Overview -World Bank 2016 (https://www.worldbank.org/en/country/srilanka /overview, (accessed 15 December 2016).

3. Ministry of Health and Indigenous Medicine, Finance Division Records 2015. Ministry of Health and Indigenous Medicine, Colombo Sri Lanka 2016.

4. Brailsford SC De Silva D. How many dentists does Sri Lanka Need? Modelling to inform policy decisions. J Oper Res Soc 2015; 66: 1566-77.

5. World Health Organization. World Health Report 2006 Working together for Health. Geneva: World Health Organization; 2006. (http://www.whqlibdoc.who.int/publications/20 06/9241563176 eng.pdf, (accessed January 2016).
6. Ranson MK, Chopra M, Atkins S, Dal Poz MR, Bennett S. Priorities for research into human resources for health in low and middle -income countries. Bull World Health Organ. 2010; 88: 435-43.

7. Sterman, JD. System Dynamics Modeling: Tools for Learning in a Complex World. California Management Review 2001; 43: 8-25.

8. Forrester JW. System dynamics - the next fifty years. System Dynamics Review 2007; 23: 35970.

9. Coyle G. Qualitative and Quantitative Modelling in System Dynamics: some research questions. System Dynamics Review 2000; 16: 225.

10. World Health Organization. The World health Report 2010- Health system financing: the path to universal health coverage. Geneva: World Health Organization; 2010. http://www.who.int/whr/2010/en/, (accessed April 13 2016).

11. Global Health Alliance. Economic, demographic and epidemiological transitions and the future of health lobour markets [Technical Working Group 1 synthesis paper for the Global Strategy on Human Resources for Health, 28 September 2014] Global Health Alliance;2014.

http://www.who.int/workforcealliance/media/ne ws/2014/WG1 Synthesis, (accessed 25 March 2015).

12. Global Health Workforce Alliance. Health workforce 2030-towards a global strategy on human resources for health [Synthesis paper]. Geneva .WHO; 2015.

http://www.int/hrh/documents/symthesis_paper them2015/en/, (accessed 15 July 2016).

13. Cometto G, Tulenko K, Muula AS, Krech R. Health Workforce Brain Drain: From Denouncing the Challenge to Solving the Problem. PLoS Med 2013; 10: e1001514

14. Morecroft, J. 2007. Strategic Modelling and Business Dynamics. A Feedback Systems Approach. Chichester: John Wiley \&Sons Ltd.

15. Brailsford, SC. Overcoming barriers to the implementation of OR simulation models in healthcare. Clin Invest Med 2005; 28: 312-5. 
Table 1. Training needs and workforce profile of the surgical group of specialties

\begin{tabular}{|c|c|c|c|c|c|c|c|}
\hline & $\begin{array}{c}\text { Current } \\
\text { training } \\
\text { rate } \\
\end{array}$ & $\begin{array}{c}\text { Propose } \\
\text { d } \\
\text { training } \\
\text { rate } \\
\end{array}$ & Attrition & Retirement & $\begin{array}{c}\text { Number } \\
\text { at end of } \\
2015 \\
\end{array}$ & $\begin{array}{c}\text { Number } \\
\text { at end of } \\
2025 \\
\end{array}$ & $\begin{array}{c}\% \\
\text { increase }\end{array}$ \\
\hline ENT & 4.2 & 5 & 13 & 16 & 48 & 66 & 38 \\
\hline Orthopaedics & 8.16 & 8 & 16 & 14 & 40 & 96 & 140 \\
\hline General Surgery & 23.65 & 26 & 52 & 59 & 147 & 280 & 95 \\
\hline Urological Surgery & 4.36 & 5 & 9 & 7 & 19 & 48 & 153 \\
\hline Cardiac Surgery & 1.87 & 4 & 9 & 9 & 16 & 23 & 44 \\
\hline Oncological Surgery & 1.29 & 4 & 8 & 4 & 12 & 23 & 92 \\
\hline Plastic Surgery & 2.55 & 4 & 5 & 4 & 12 & 30 & 150 \\
\hline GI Surgery & 2.18 & 3 & 10 & 0 & 7 & 21 & 200 \\
\hline Paediatric Surgery & 1.82 & 1.82 & 6 & 8 & 13 & 30 & 107 \\
\hline Neuro Surgery & 1.87 & 5 & 5 & 7 & 17 & 29 & 71 \\
\hline $\begin{array}{l}\text { Vascular \& Transplant } \\
\text { Surgery }\end{array}$ & 2.82 & 3 & 9 & 3 & 8 & 23 & 167 \\
\hline Thoracic & 0 & 1.5 & 1 & 0 & 4 & 8 & 100 \\
\hline Total & 54.77 & 70.32 & 143 & 131 & 343 & 677 & $97 \%$ \\
\hline
\end{tabular}

CTR- Current Training Rate ( average 2010-2015)

Table 2. Training needs and workforce profile of the medical group of specialties

\begin{tabular}{|c|c|c|c|c|c|c|c|}
\hline & $\begin{array}{c}\text { Current } \\
\text { training } \\
\text { rate }\end{array}$ & $\begin{array}{c}\text { Proposed } \\
\text { training } \\
\text { rate }\end{array}$ & Attrition & Retirement & $\begin{array}{c}\text { Number } \\
\text { at end of } \\
2015 \\
\end{array}$ & $\begin{array}{c}\text { Numb } \\
\text { er at } \\
\text { end of } \\
2025 \\
\end{array}$ & $\%$ increase \\
\hline General Medicine & 59.43 & 27 & 84 & 65 & 248 & 508 & 105 \\
\hline Cardiology & 10.9 & 8 & 12 & 20 & 47 & 116 & 147 \\
\hline Endocrinology & 5.89 & 6 & 12 & 0 & 15 & 62 & 31 \\
\hline Gastroenterology & 3.68 & 4 & 10 & 1 & 11 & 37 & 236 \\
\hline Respiratory Medicine & 5.89 & 5.89 & 11 & 11 & 30 & 70 & 133 \\
\hline Rheumatology & 7.36 & 5 & 6 & 11 & 24 & 69 & 188 \\
\hline Nephrology & 4.36 & 5 & 9 & 5 & 23 & 55 & 139 \\
\hline Neurology & 7.36 & 4 & 3 & 9 & 30 & 78 & 160 \\
\hline Neurophysiology & 1.03 & 1.03 & 1 & 0 & 3 & 14 & 367 \\
\hline $\begin{array}{l}\text { Cardiac } \\
\text { Electrophysiology }\end{array}$ & 1.25 & 1.25 & 2 & 3 & 5 & 12 & 140 \\
\hline & 107.15 & 67.17 & 150 & 125 & 436 & 1021 & $134 \%$ \\
\hline
\end{tabular}

CTR- Current Training Rate ( ave 2010-2015) PTR Proposed Training Rate 
Table 3. Other Group of Specialties - Training needs and workforce profile

\begin{tabular}{|c|c|c|c|c|c|c|c|}
\hline & $\begin{array}{c}\text { Current } \\
\text { training } \\
\text { rate }\end{array}$ & $\begin{array}{c}\text { Proposed } \\
\text { training } \\
\text { rate }\end{array}$ & Attrition & Retirement & $\begin{array}{c}\text { Number } \\
\text { at end of } \\
2015 \\
\end{array}$ & $\begin{array}{c}\text { Number } \\
\text { at end of } \\
2025 \\
\end{array}$ & $\begin{array}{c}\% \\
\text { Increase }\end{array}$ \\
\hline GYN \& OBS & 21.6 & 25 & 57 & 52 & 131 & 278 & 112 \\
\hline Eye & 10.6 & 13 & 13 & 35 & 61 & 131 & 114 \\
\hline Venereology & 6.4 & 6 & 5 & 9 & 18 & 66 & 266 \\
\hline Dermatology & 8.8 & 5 & 14 & 16 & 65 & 100 & 54 \\
\hline Psychiatry & 19 & 14 & 31 & 19 & 63 & 177 & 181 \\
\hline Transfusion & & & & 9 & & & \\
\hline Medicine & 5 & 4 & 4 & & 21 & 54 & 157 \\
\hline Radiology & 16.8 & 12 & 38 & 32 & 110 & 187 & 70 \\
\hline Anaesthesiology & 39 & 27 & 86 & 60 & 110 & 310 & 182 \\
\hline Forensic Medicine & 4.6 & 5 & 11 & 15 & 39 & 69 & 77 \\
\hline Oncology & 4.6 & 4 & 8 & 10 & 41 & 67 & 63 \\
\hline Histopathology & 6.5 & 11 & 42 & 12 & 62 & 83 & 34 \\
\hline Haematology & 12 & 8 & 19 & 13 & 50 & 124 & 148 \\
\hline Microbiology & 10.8 & 9 & 19 & 9 & 16 & 74 & 363 \\
\hline Chemical Path & 6 & 6 & 17 & 3 & 15 & 58 & 286 \\
\hline Immunology & 0.33 & 0.33 & & & 3 & 5 & 67 \\
\hline Mycology & 0.33 & 1 & & & 1 & 7 & 600 \\
\hline Virology & 0.66 & 1 & & & 10 & 16 & 60 \\
\hline Parasitology & & & & & 3 & 5 & 67 \\
\hline Total & 184.79 & 161.5 & 364 & 294 & 819 & 1811 & $121 \%$ \\
\hline
\end{tabular}

CTR- Current Training Rate ( ave 2010-2015) PTR Proposed Training Rate

Note-Immunology, Mycology, Parasitology and Virology disciplines are not modelled 
Table 4. Pediatric Group of Specialties- Training needs and workforce profile

\begin{tabular}{|c|c|c|c|c|c|c|c|}
\hline & $\begin{array}{c}\text { Curre } \\
\text { nt } \\
\text { trainin } \\
\text { g rate }\end{array}$ & $\begin{array}{l}\text { Prop } \\
\text { osed } \\
\text { traini } \\
\text { ng } \\
\text { rate } \\
\end{array}$ & Attrition & Retirement & $\begin{array}{l}\text { Number } \\
\text { at end of } \\
2015\end{array}$ & $\begin{array}{l}\text { Number } \\
\text { at end of } \\
2025\end{array}$ & $\begin{array}{c}\% \\
\text { Increase }\end{array}$ \\
\hline General paediatrics & 37.4 & 17 & 70 & 73 & 167 & 295 & 77 \\
\hline Pae. Endocrinology & 1.21 & 1.21 & 1 & 0 & 2 & 12 & 500 \\
\hline Pae Pulmonology & 0.52 & 2 & - & 0 & 0 & 11 & - \\
\hline Pae Neurology & 0.91 & 2 & 2 & 0 & 6 & 15 & 150 \\
\hline Pae Cardiology & 0.78 & 2 & 2 & 0 & 8 & 17 & 112 \\
\hline Pae intensive care & 0.52 & 5 & 2 & 0 & 3 & 24 & 700 \\
\hline Pae Nephrology & 0.84 & 4 & 3 & 0 & 3 & 17 & 466 \\
\hline \multirow[t]{2}{*}{ Neonatologists } & 4.54 & 5 & 11 & 7 & 16 & 43 & 168 \\
\hline & 46.72 & 38.21 & 91 & 80 & 205 & 434 & $112 \%$ \\
\hline
\end{tabular}

CTR- Current Training Rate ( ave 2010-2015) PTR Proposed Training Rate. Pae- Paediatric

Table 5. Dental Specialties- Training needs and workforce profile

\begin{tabular}{lccccccc}
\hline & $\begin{array}{c}\text { Curren } \\
\mathbf{t} \\
\text { trainin } \\
\text { g rate }\end{array}$ & $\begin{array}{c}\text { Propos } \\
\text { ed } \\
\text { trainin } \\
\text { g rate }\end{array}$ & Attrition & Retirement & $\begin{array}{c}\text { Number } \\
\text { at end of } \\
\mathbf{2 0 1 5}\end{array}$ & $\begin{array}{c}\text { No.as at } \\
\text { end 2025 }\end{array}$ & $\begin{array}{c}\text { \% } \\
\text { Increase }\end{array}$ \\
\hline Restorative Dentistry & 3.6 & 3 & 10 & 3 & 8 & 28 & 250 \\
\hline Orthodontics & 4 & 3 & 2 & 10 & 21 & 44 & 109 \\
\hline OMF & 4.17 & 4 & 5 & 13 & 28 & 52 & 85 \\
\hline Total & $\mathbf{1 1 . 7 7}$ & $\mathbf{1 0}$ & $\mathbf{1 7}$ & $\mathbf{2 6}$ & $\mathbf{5 7}$ & $\mathbf{1 2 4}$ & $\mathbf{1 1 8 \%}$ \\
\hline
\end{tabular}

CTR- Current Training Rate ( ave 2010-2015) PTR Proposed Training Rate 